\title{
The neural plasticity of other-race face recognition
}

\author{
James W. Tanaka and Lara J. Pierce \\ University of Victoria, Victoria, British Columbia, Canada
}

\begin{abstract}
Although it is well established that people are better at recognizing own-race faces than at recognizing otherrace faces, the neural mechanisms mediating this advantage are not well understood. In this study, Caucasian participants were trained to differentiate African American (or Hispanic) faces at the individual level (e.g., Joe, $B o b)$ and to categorize Hispanic (or African American) faces at the basic level of race (e.g., Hispanic, African American). Behaviorally, subordinate-level individuation training led to improved performance on a posttraining recognition test, relative to basic-level training. As measured by event-related potentials, subordinate- and basic-level training had relatively little effect on the face N170 component. However, as compared with basiclevel training, subordinate-level training elicited an increased response in the posterior expert N250 component. These results demonstrate that learning to discriminate other-race faces at the subordinate level of the individual leads to improved recognition and enhanced activation of the expert N250 component.
\end{abstract}

Although virtually everyone is an expert in face recognition, people demonstrate an even more specialized form of face expertise for the recognition of own-race faces. That is, a well-established finding in the face-processing literature is that people are better at recognizing faces from their own race than at recognizing faces from other races (Bothwell, Brigham, \& Malpass, 1989; Meissner \& Brigham, 2001). The own-race effect (ORE) is independent of the race of the participant and race of the face. For example, Caucasian participants show an advantage for the recognition of Caucasian faces over the recognition of Asian faces, whereas Asian participants show a reverse recognition advantage for Asian faces over Caucasian faces (O'Toole, Deffenbacher, Valentin, \& Abdi, 1994; Walker \& Tanaka, 2003). The dissociation of the ORE provides compelling evidence that the own-race advantage is determined by the perceptual experiences of the observer, and not by the facial geometry of the racial group (Chiroro \& Valentine, 1995; Furl, Phillips, \& O’Toole, 2002; Meissner \& Brigham, 2001; Slone, Brigham, \& Meissner, 2000; Valentine, 1991; Wright, Boyd, \& Tredoux, 2001). However, it is less clear whether it is the quantity or the quality of the own- versus other-race face experience that influences the magnitude of the ORE.

Several studies have shown that the amount of exposure to other-race individuals can ameliorate the ORE. For instance, Caucasian individuals who live in a multiracial neighborhood (Chiroro \& Valentine, 1995) or watch sporting events played by African American athletes (MacLin, Van Sickler, MacLin, \& Li, 2004) exhibit a reduced ORE, as compared with race-matched control participants. However, other studies have shown that substantial inter- racial contact does not necessarily ensure that other-race face recognition will improve. Caucasian participants with extensive interracial contact with Chinese individuals (Ng \& Lindsay, 1994) do not show an improved ability to recognize faces from the other race. Developmental studies similarly have shown that African American children reared in a multicultural environment show a level of recognition of Caucasian faces that is the same as that of children reared in a monocultural African American environment (Cross, Cross, \& Daly, 1971). Meta-analysis of the ORE studies revealed that self-report measures of other-race contact accounted for less than $3 \%$ of the total variance found in the ORE (Meissner \& Brigham, 2001). The equivocal findings from the social contact studies indicate that other factors beyond pure exposure to otherrace faces modulate the magnitude of the ORE.

Beyond experience, it has been suggested that the ownrace face advantage is a consequence of categorization processes. That is, people tend to categorize members of their own race at the subordinate level of the individual (e.g., Bob, Joe) and categorize other-race members at the basic level of race (e.g., Caucasian, African American, Hispanic). Levin (2000) has argued that as a consequence of categorization processes, race-defining information is abstracted from the other-race face at the cost of individuating information. Whereas basic-level categorization of other-race faces produces a deficit in a recognition task, it can result in a benefit for other types of tasks. For example, in a visual search task, it was found that Caucasian participants detected an African American face target among Caucasian face distractors more quickly than they detected a Caucasian target among African American dis- 
tractors (Levin, 2000). Hence, when the relevant level of discrimination is race, participants demonstrate an otherrace advantage.

The different levels at which own- and other-race faces are categorized are similar to the differences that distinguish experts and novices. Studies have shown that whereas experts tend to categorize objects in their domain of expertise at the specific, subordinate level of abstraction (e.g., a bird expert will identify a bird as a robin or sparrow), novices will categorize the same object at the generic, basic level (e.g., a novice will categorize the same robin or sparrow as a bird) (Johnson \& Mervis, 1997; Tanaka \& Taylor, 1991). Recent training studies have shown that participants who learn to categorize owls or wading birds at the subordinate level of species (e.g., great blue crown heron, eastern screech owl) demonstrate improved discrimination of novel bird exemplars from learned and related species. In contrast, participants who learned to categorize the same birds at the basic level showed no evidence of perceptual transfer (Scott, Tanaka, Sheinberg, \& Curran, 2006; Tanaka, Curran, \& Sheinberg, 2005). These studies indicate that training in subordinatelevel categorization induces a finer grain of perceptual analysis that is not afforded by basic-level learning.

To what degree can other-race face recognition be improved through subordinate-level training? In a previous training study, participants were trained to categorize African American (or Hispanic) and Hispanic (or African American) faces at either the subordinate level of the individual or the basic level of race (Tanaka \& Droucker, 2009). After five training sessions, the participants who had received subordinate-level training demonstrated improved recognition of novel other-race faces, whereas basic-level training either produced no change or impaired performance. These results suggest that, like other forms of perceptual expertise, recognition of other-race faces can be ameliorated through subordinate-level training.

\section{Event-Related Potentials and Own- Versus Other-Race Face Recognition}

Studies employing event-related potentials (ERPs) have shown that approximately $170 \mathrm{msec}$ after stimulus onset, faces elicit a greater negative brain potential (N170) in right-posterior electrodes, relative to nonface stimuli (Bentin, Allison, Puce, Perez, \& McCarthy, 1996; Rossion, Joyce, Cottrell, \& Tarr, 2003). It has been speculated that the face N170 indexes the global properties shared by all faces, rather than the individuating properties of a particular face (Bentin \& Deouell, 2000; Eimer, 2000). Consistent with this interpretation, studies have shown that the race of the face has little effect on the latency or the amplitude of the face N170 response (Caldara, Rossion, Bovet, \& Hauert, 2004; Caldara et al., 2003; James, Johnstone, \& Hayward, 2001) or its related positive-going front-central vertex positive potential (VPP; Ito, Thompson, \& Cacioppo, 2004). These results suggest that the N170 is not sensitive to differences in racial structure of faces or to differences in people's experience of race (but see Ito \& Urland, 2005, for an exception).
Differences in processing of own- and other-race faces emerge around $200 \mathrm{msec}$ or later. For example, the N200 component recorded from front-central midline sites is greater to own- than to other-race faces (Ito et al., 2004; Ito \& Urland, 2003, 2005; James et al., 2001), whereas the P200 component, recorded from parietal sites, shows the opposite effect, with greater activity to other-race black faces than to own-race white faces (Ito \& Urland, 2003, 2005). At the posterior occipital electrode (POZ), a positive deflection was found in response to other-race Asian faces, occurring approximately $200 \mathrm{msec}$ post-stimulusonset (Caldara et al., 2004). The N400 component has been shown to be larger to own-race faces in some cases (Correll, Urland, \& Ito, 2006) and to other-race faces in other cases (James et al., 2001). The varied, and sometimes conflicting, responses of the post-N170 ERP components indicate that they are sensitive to the context and task demands of the experiment, tapping more into the semantics associated with own- and other-race faces than into their perception (Ito \& Urland, 2005).

Whereas the studies above have focused on individuals who are already own-race face experts, little is known about how one acquires the ability to recognize other-race faces and the neurophysiological changes that accompany enhanced other-race recognition. ERP studies in object recognition have shown that expert training promotes greater bilateral activity in two posterior components: the N170 and a later negative-going N250. It is hypothesized that the N170 provides an index of experts' category experience, where experts are more frequently exposed to objects from their domain of expertise than are novices (Scott et al., 2006; Tanaka \& Curran, 2001). In contrast, the N250 is a marker of category specificity in which objects (Scott, Tanaka, Sheinberg, \& Curran, 2006, 2008) or faces (Kaufmann \& Schweinberger, 2008; Tanaka, Curran, Porterfield, \& Collins, 2006) that are differentiated at the subordinate level produce a greater N250 negativity, relative to objects that are categorized at the basic level. Similar results have been reported in repetition-priming studies, in which repeated exposures of familiar faces have elicited a larger negative brain wave (N250r) at inferior temporal sites, as compared with repetitions of unfamiliar faces (Schweinberger, Huddy, \& Burton, 2004; Schweinberger, Pickering, Jentzsch, Burton, \& Kaufmann, 2002). Collectively, these results indicate that the N250 component indexes an individual face representation, rather than a general representation of the face category (Bentin \& Deouell, 2000; Eimer, 2000).

In the present study, participants were trained to individuate other-race African American (or Hispanic) faces as individuals and to categorize Hispanic (or African American) faces in terms of race. The number of learning trials was equated, so that African American and Hispanic faces were presented an equal number of times during training and differed only in the level at which they were classified. ERPs to the African American and Hispanic faces were recorded during a recognition test administered prior to and after training. Behaviorally, we predicted that the ORE would be diminished for faces trained at the sub- 
A

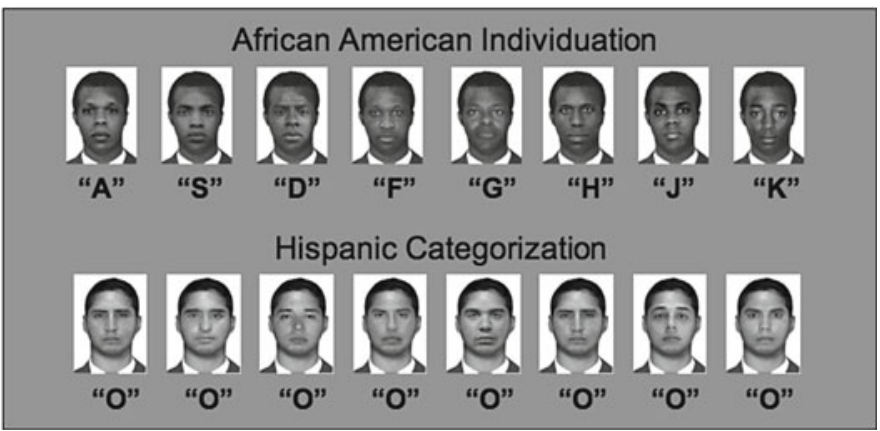

B

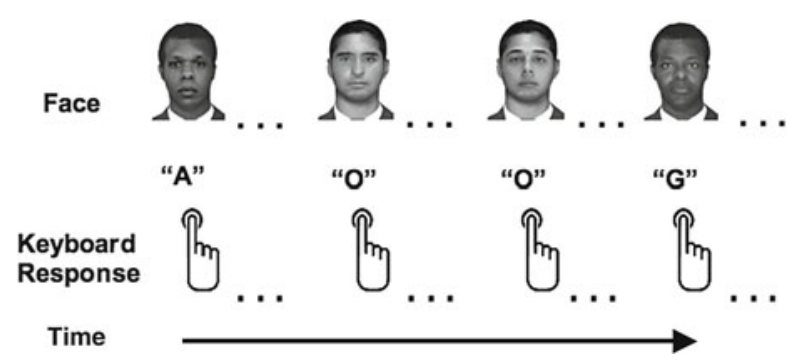

Figure 1. (A) In the African American individuation/Hispanic categorization training condition, eight African American faces were assigned a unique letter label ( $A, S, D, F, G, H, J, K)$, and eight Hispanic faces were assigned to the same letter label $(O)$. (B) During training, the participants were randomly presented with either an African American or a Hispanic face and were asked to respond with the appropriate letter label. If the participants responded incorrectly, corrective feedback was provided. Half of the participants were trained to individuate African American faces and categorize Hispanic faces, and the other half received the opposite training.

ordinate level of the individual, relative to faces trained at the basic level of race. With respect to ERP components, there were two primary predictions under test. First, given that participants have previous and pervasive experience of faces, basic- and subordinate-level training should have little effect on the N170 component. Second, as a marker of subordinate-level differentiation, an enhanced N250 should be produced after subordinate-level training, as opposed to basic-level training.

\section{METHOD}

\section{Participants}

Twenty-four University of Victoria undergraduate students $18-29$ years of age $(M=21.0)$ participated in this experiment. All had normal or corrected-to-normal vision, were right-handed, and had no history of brain injury or trauma. The participants received course credit plus $\$ 20$ for their participation. One participant was excluded due to a technical problem with one of her data files.

The participants completed a background questionnaire regarding their experience with members from other racial groups. Nineteen participants $(83 \%)$ identified themselves as Caucasian, whereas 4 participants (17\%) identified themselves as belonging to other racial groups (Korean, First Nations Aboriginal, Turkish, and Thai). Two participants $(9 \%)$ reported daily and $4(17 \%)$ reported weekly contact with someone from a racial group other than Caucasian (Chinese, Japanese, Korean, East Indian). None of the participants reported having daily experience with Hispanic or African American individuals.

\section{Stimuli}

Six hundred original photographs of African American and Hispanic faces were obtained from the Department of Corrections' face databases from the states of Florida, Arkansas, Georgia, and Kansas. Adobe PhotoShop was used to create 440 grayscaled images with these faces. All the faces displayed neutral expressions and were males of either Hispanic or African American ethnicity with the ages of 20-35 years. Internal face features were digitally placed in a standard face template with identical hairstyle, face contour, and clothing (see Figure 1A). External cues (e.g., hairstyle, clothing) were kept constant in order to promote recognition strategies based on facial features, rather than nonface strategies based on incidental cues (Bonner, Burton, \& Bruce, 2003; O’Donnell \& Bruce, 2001). Luminance was controlled within each racial group (African Ameri$\mathrm{can}=121$ mean luminance, Hispanic $=151$ mean luminance) . Images were formatted as $225 \times 311$ pixel bitmaps and were presented on a computer monitor (LG monitor, $1,024 \times 768$ pixel screen resolution) positioned $60 \mathrm{~cm}$ from the participant. Visual stimuli subtended a visual angle of approximately $6.65^{\circ}$ and $7.59^{\circ}$ in the vertical and horizontal dimensions, respectively.

\section{Procedure}

Pretraining face recognition test. Prior to training, the participants performed an old/new face recognition test. During the study phase of the test, the participants viewed 12 Hispanic and 12 African American faces that were randomly presented on a computer screen. 
Each study trial began with a fixation cross presented for $250 \mathrm{msec}$, followed by the study faces, which appeared for $2 \mathrm{sec}$. The study face was followed by a blank screen and an intertrial interval of $1 \mathrm{sec}$.

A recognition test was administered immediately following the study phase. The participants were told that they would see a series of faces and that they were to indicate whether the face had appeared in the study phase. Their task was to press the key labeled "old" on the response box if the face had appeared in the study phase and the key labeled "new" if it had not. Each trial began with a fixation cross that was shown for $250 \mathrm{msec}$, followed by a test face appearing on the screen for $3 \mathrm{sec}$. The participants could respond while the face was on the screen or during an additional 2-sec blank screen interval. Following the participants' response, there was a 1-sec intertrial interval. During the test phase, 24 Hispanic faces (12 old and 12 new) and 24 African American faces (12 old and 12 new) were randomly presented. The old/new recognition test was repeated three times with a new set of 24 Hispanic and 24 African American faces. Thus, the entire recognition test consisted of a total of 144 trials (72 Hispanic faces, 72 African American faces).

During the recognition phase of the pretraining test, the electroencephalogram (EEG) was recorded from 41 electrode sites, using Brain Vision Recorder software (Version 1.3; Brain Products, Munich, Germany). Electrodes were set in an Easy Cap and referenced to a common ground. Eye movements were recorded from electrodes set on the left and right temples and beneath the right eye. Electrode impedances were maintained below $10 \mathrm{k} \Omega$. EEG data were sampled at $250 \mathrm{~Hz}$, amplified (Quick Amp, Brain Products) and were filtered through a bandpass of $0.017-67.5 \mathrm{~Hz}$. After recording, the EEG data were filtered $(0.1-20 \mathrm{~Hz}$ passband), rereferenced to unlinked earlobes, and ocular correction was performed (Gratton, Coles, \& Donchin, 1983). Subsequent artifact rejection removed trials on which the change in voltage was $35 \mu \mathrm{V}$ or greater. All of the participants had a minimum of 68 artifact-free trials in the Hispanic and African American conditions. The ERPs were segmented into an 800-msec epoch surrounding stimulus presentation and were baseline-corrected with respect to a 200 -msec prestimulus recording interval that included the offset of the fixation cross. The offset generated a prestimulus negative deflection that elevated the overall positivity of the waveforms when included in the baseline correction. However, this had no effect on the comparisons between the training conditions (basic vs. subordinate) or test times (pretraining vs. posttraining).

Behavioral training. Behavioral training consisted of five 45min sessions on consecutive days following the pretraining assessment. The participants were randomly assigned to either the African American individuation/Hispanic categorization or the Hispanic individuation/African American categorization training condition. Training involved a learning task, a naming task, and a timedresponse task, designed so that the participants would learn to individuate eight novel faces of Hispanic or African American ethnicity per day, while categorizing the converse. Importantly, none of the faces employed for training were used in the recognition test.

Learning task. At the beginning of the first training block, the participants were shown two Hispanic and two African American faces with corresponding labels underneath. Subsequent training blocks presented one new face from each race, until eight faces from each race had been learned. Faces belonging to the individuation condition were presented with labels of "A," "S," "D," "F," "G," "H,"
"J," or "K." Faces in the categorization condition were always presented with the letter "O." Each face was introduced twice in this way, and the participants were to press the key corresponding to the label. The stimuli remained on the screen until the participants' response was made. A feedback screen with corrective information for incorrect responses followed each response for $750 \mathrm{msec}$. There was a 1,000-msec interval between presentations.

Naming task. Each block of the learning task was followed by a naming task. During the naming task, the stimuli from the learning task were presented, in random order, with no label until a response was made. The participants were required to press the button corresponding to the identity that had previously been associated with the face. Following their response, the participants were provided with feedback for $1,000 \mathrm{msec}$ to indicate whether they were correct or incorrect on each trial. On incorrect trials, the correct label was provided. The participants were required to correctly label the faces with $100 \%$ accuracy before continuing to the next block. If they failed to do so, they repeated the block until successful. This proceeded until the participants had learned to individuate or categorize eight faces from each racial group.

Timed-response task. Following seven blocks of learning and accurate naming of the eight individuated and eight categorized faces, a timed-response task was performed for three blocks. During this task, the participants were again required to respond to the same stimuli presented throughout the session with the assigned keys, but this time under a response deadline of $3,000 \mathrm{msec}$ for the first block, 2,500 msec for the second block, and 2,000 msec for the final block. Feedback was then presented for 1,000 msec for the first block and $1,500 \mathrm{msec}$ for subsequent blocks. The participants were required to complete this task at $100 \%$ accuracy, indicating that they had successfully learned to differentiate all the faces within the session.

Posttraining old/new recognition test. Following five sessions of behavioral training, the participants were given a posttraining old/ new recognition task. Procedures for the posttraining recognition test were identical to those used in the pretraining recognition test. To provide a direct basis of comparison, the same face stimuli as those employed in the pretraining test were used in the posttraining measure.

\section{RESULTS}

\section{Behavioral Analysis}

To evaluate training effects, performance on the old/ new recognition test was submitted to a repeated measures ANOVA with the factors of training (individuation, categorization), test time (pretraining, posttraining), and response type (hits, correct rejections) (see Table 1). A significant main effect of test time $[F(1,22)=14.20$, $p<.01]$ was found, showing that, overall, recognition was better after training (individuation or categorization) than before training. Although the main effect of training was not reliable $[F(1,22)=2.71, p>.10]$, there was a marginally significant training $\times$ test time interaction $[F(1,22)=3.99, p=.058]$, indicating that, after training, the participants in the individuation condition improved to a greater extent than did those in the categorization condi-

Table 1

Behavioral Measures (Percent Correct for Hits and Correct Rejections, As Well As d' Scores) for Pre- Versus Postassessment in the Individuation and Categorization Conditions

\begin{tabular}{|c|c|c|c|c|c|c|c|c|}
\hline & \multicolumn{4}{|c|}{ Individuation } & \multicolumn{4}{|c|}{ Categorization } \\
\hline & $\begin{array}{l}\text { Hits } \\
(\%)\end{array}$ & $\begin{array}{c}\text { Correct } \\
\text { Rejections (\%) }\end{array}$ & $d^{\prime}$ & $B_{\mathrm{r}}$ & $\begin{array}{l}\text { Hits } \\
(\%)\end{array}$ & $\begin{array}{c}\text { Correct } \\
\text { Rejections (\%) }\end{array}$ & $d^{\prime}$ & $B_{\mathrm{r}}$ \\
\hline Preassessment & 56 & 62 & 0.51 & 0.46 & 58 & 60 & 0.49 & 0.49 \\
\hline Postassessment & 66 & 68 & 0.93 & 0.43 & 58 & 68 & 0.79 & 0.42 \\
\hline
\end{tabular}




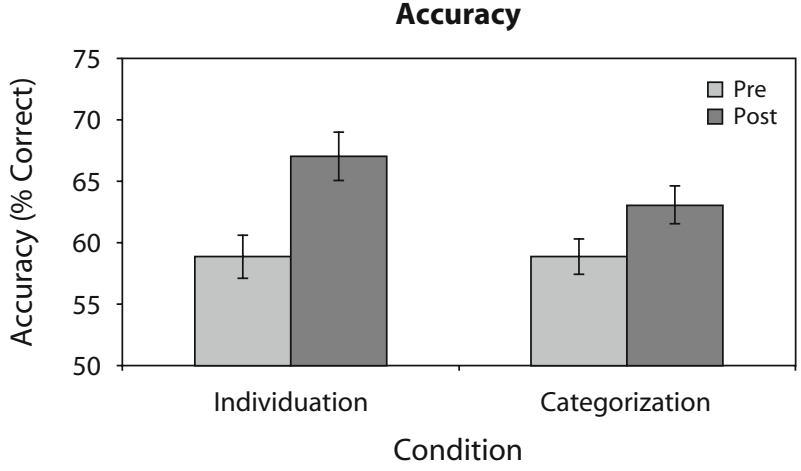

Figure 2. Accuracy (percentage correct on old and new trials) from pre- to postassessment for the individuation and categorization conditions.

tion (see Figure 2). Planned comparisons confirmed that the individuation and categorization conditions showed improvement after training, as measured by gains from pre- to posttraining performance $(p<.01)$. However, recognition performance in the individuation condition was significantly better, after individuation training, than basic-level training recognition performance in the categorization condition $(p<.01)$.

A second repeated measures ANOVA was performed on $d^{\prime}$ scores with the main effects of training condition (individuation, categorization) and test time (pretraining, posttraining). A main effect of test time was found $[F(1,22)=16.31, p<.01]$, indicating that, overall, recognition improved after training, relative to before training. The main effect of training $[F(1,22)=1.77]$ and the interaction between training condition and test time $[F(1,22)=$ $1.34]$ were not reliable $(p>.10)$. Although there was no difference in performance between the individuation and categorization conditions at the time of the pretraining test (individuation mean $=.51$, categorization mean $=.49$; $p>.10)$, there was a trend toward a recognition advantage after individuation training, rather than after categorization training (individuation mean $=.93$, categorization mean $=.79 ; p=.08)$.

To test whether training influenced the response bias of the participants, the response bias measure $B_{\mathrm{r}}$ was calcu- lated, and a repeated measures ANOVA was performed on the factors of training (individuation, categorization) and test time (pretraining, posttraining). There was no main effect of training $[F(1,22)=0.29, p>.10]$. However, the main effect of test time was reliable $[F(1,22)=5.56, p<$ $.05]$, indicating that the participants in both conditions responded more conservatively during the pretraining test. Planned comparison analyses revealed that there was no difference in response bias between the individuation and categorization conditions in either the pre- or the posttraining tests $(p>.10)$.

\section{ERP Analysis}

ERP analysis focused on the visual P100, N170, P200, and N250 components at posterior channels PO7 and PO8, where these components showed maximal activity (see Figure 3). ERPs were recorded during the test trials (correct and incorrect) of the old/new face recognition test before and after training. The latency and mean amplitudes for each component were submitted to an ANOVA with training (individuation, categorization), test time (pretraining, posttraining), and hemisphere (left, right) as within-group factors.

P100 component. P100 latency was identified as the maximum positive peak amplitude during a window of between 50 and $150 \mathrm{msec}$ post-stimulus-onset. A main effect of training was found $[F(1,22)=5.03, p<.05]$, indicating that the $\mathrm{P} 100$ occurred earlier in the individuation condition $(106 \mathrm{msec})$ than in the categorization condition $(109 \mathrm{msec})$. No other effects reached significant levels. To compute mean amplitudes, time windows of two standard deviations around the mean latencies for the individuation (76-135 msec) and categorization (79$140 \mathrm{msec}$ ) training conditions were selected. A repeated measures ANOVA showed that there were no main effects of training $[F(1,22)=0.43, p>.10]$, test time $[F(1,22)=$ $0.84, p>.10]$, or hemisphere $[F(1,22)=2.60, p>.10]$. There was a significant training $\times$ hemisphere interaction $[F(1,22)=5.19, p<.05]$, indicating that the mean amplitude of P100 was smaller in the categorization condition than in the individuation condition, but only in the left hemisphere (see Table 2). ${ }^{1}$ No other interactions were reliable.

Table 2

Mean Latencies and Amplitudes for All Components for Pre- Versus Postassessment for the Individuation and Categorization Conditions

\begin{tabular}{|c|c|c|c|c|c|c|c|c|c|}
\hline \multirow[b]{3}{*}{ Component } & \multirow[b]{3}{*}{ Electrode } & \multicolumn{4}{|c|}{ Individuation } & \multicolumn{4}{|c|}{ Categorization } \\
\hline & & \multicolumn{2}{|c|}{ Preassessment } & \multicolumn{2}{|c|}{ Postassessment } & \multicolumn{2}{|c|}{ Preassessment } & \multicolumn{2}{|c|}{ Postassessment } \\
\hline & & $\begin{array}{c}\text { Latency } \\
(\mathrm{msec})\end{array}$ & $\begin{array}{l}\text { Amp. } \\
(\mu \mathrm{V})\end{array}$ & $\begin{array}{c}\text { Latency } \\
(\mathrm{msec})\end{array}$ & $\begin{array}{l}\text { Amp. } \\
(\mu \mathrm{V})\end{array}$ & $\begin{array}{l}\text { Latency } \\
\text { (msec) }\end{array}$ & $\begin{array}{l}\text { Amp. } \\
(\mu \mathrm{V})\end{array}$ & $\begin{array}{l}\text { Latency } \\
(\mathrm{msec})\end{array}$ & $\begin{array}{l}\text { Amp. } \\
(\mu \mathrm{V})\end{array}$ \\
\hline \multirow[t]{2}{*}{ P100 } & PO7 & 105 & 8.55 & 102 & 9.52 & 110 & 8.53 & 103 & 8.71 \\
\hline & PO8 & 107 & 9.35 & 108 & 9.84 & 113 & 9.73 & 111 & 9.65 \\
\hline \multirow[t]{2}{*}{ N170 } & PO7 & 168 & 2.56 & 161 & 3.42 & 165 & 2.34 & 159 & 2.81 \\
\hline & PO8 & 168 & 3.00 & 166 & 2.97 & 165 & 3.20 & 163 & 3.96 \\
\hline \multirow[t]{2}{*}{ P200 } & PO7 & 224 & 7.38 & 215 & 6.96 & 221 & 7.22 & 220 & 7.77 \\
\hline & PO8 & 222 & 8.91 & 219 & 9.29 & 220 & 9.10 & 215 & 10.99 \\
\hline \multirow[t]{2}{*}{ N250 } & PO7 & N/A & 7.08 & N/A & 5.24 & $\mathrm{~N} / \mathrm{A}$ & 7.14 & N/A & 7.11 \\
\hline & PO8 & N/A & 8.26 & N/A & 6.92 & N/A & 8.29 & N/A & 9.69 \\
\hline
\end{tabular}



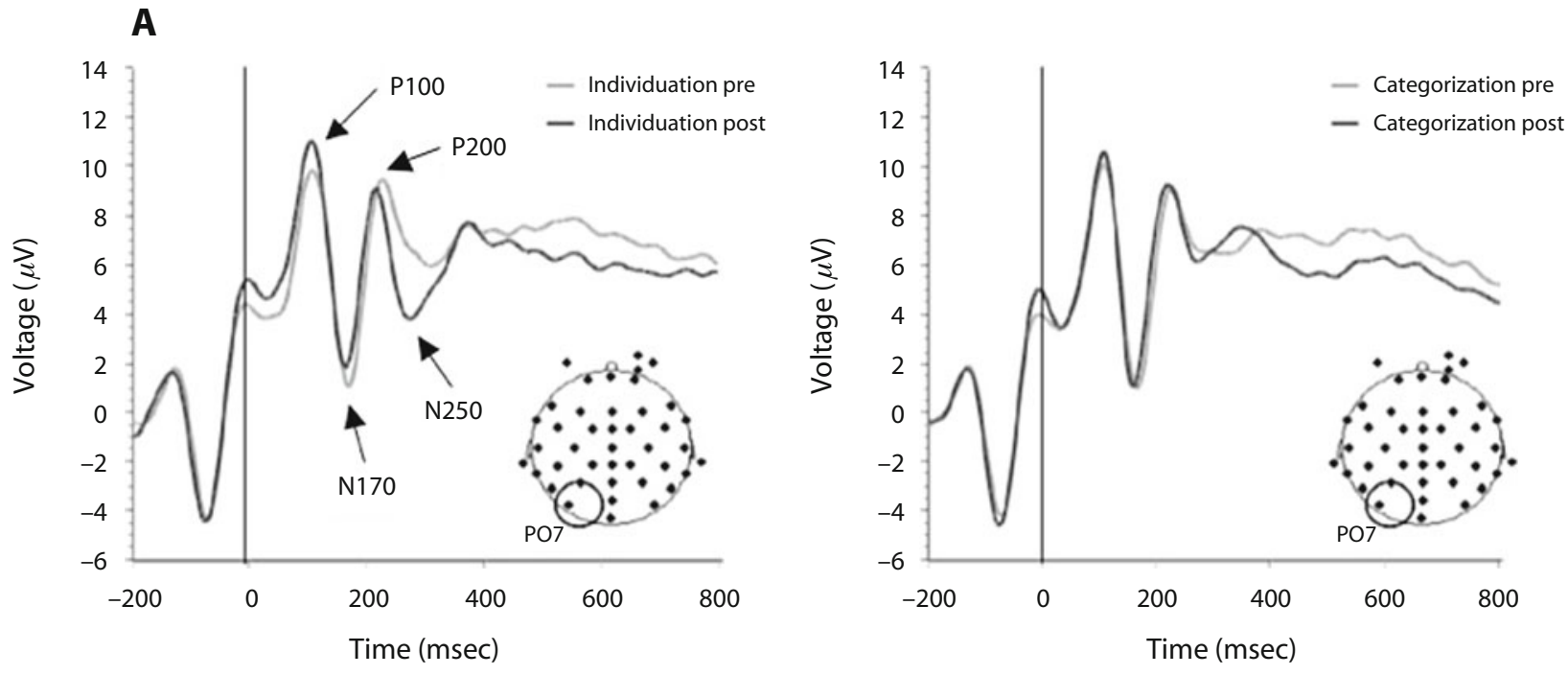

B
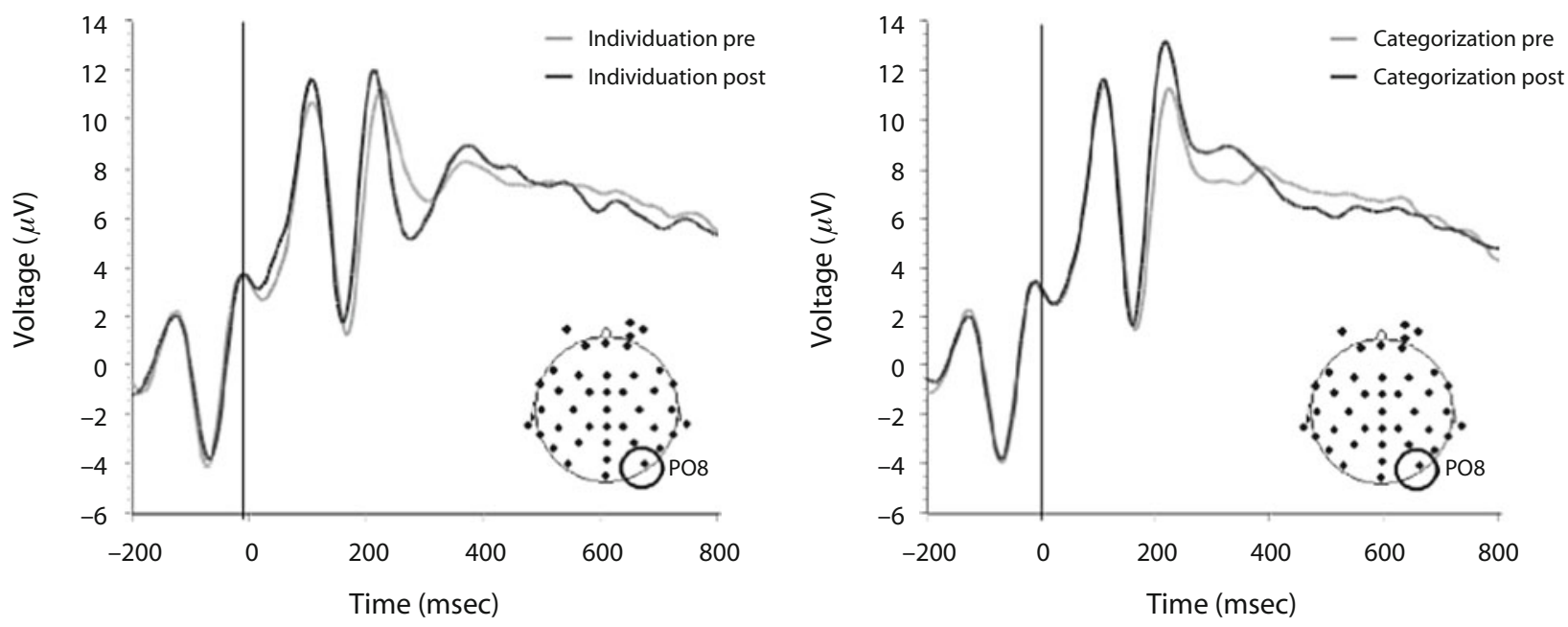

Figure 3. (A) Waveforms from the left hemisphere (PO7) for the individuation (left panel) and categorization (right panel) conditions at pre- versus postassessment. (B) Waveforms from the left hemisphere (PO8) for the individuation (left panel) and categorization (right panel) conditions at pre- versus postassessment.

N170 component. The N170 latency was identified as the maximum negative peak amplitude during a window of 120-200 msec post-stimulus-onset. Although the test time difference was small (pretraining, $M=162 \mathrm{msec}$; posttraining, $M=166 \mathrm{msec}$ ), this factor reached reliable levels $[F(1,22)=4.60, p<.05]$, indicating an earlier latency after than before training. Given this difference, separate time windows of \pm 2 standard deviations around the mean latency were calculated for the pretraining (141-192 msec) and posttraining (134-190 msec) conditions (see Table 2). A repeated measures ANOVA for mean activity revealed no main effects of training $[F(1,22)=$ $0.089, p>.10]$, test time $[F(1,22)=1.14, p>.10]$, or hemisphere $[F(1,22)=0.386, p>.10]$. However, there was a significant training $\times$ hemisphere interaction $[F(1,22)=7.23, p<.05$; but see note 1$]$. No other interactions were reliable.
P200 component. The P200 latencies were identified as the maximum positive peak during a time window of 150 $250 \mathrm{msec}$ following stimulus presentation. A repeated measures ANOVA showed no significant latency differences for any of the main factors or their interactions. A mean activity (in $\mu \mathrm{V}$ ) was computed using a time window \pm 2 standard deviations around the mean latency $(219 \mathrm{msec})$, leading to an analysis window of $182-257 \mathrm{msec}$. There was a significant effect of hemisphere $[F(1,22)=9.33, p<$ $.01]$, where overall activity was greater in the right hemisphere than in the left hemisphere. There was a reliable training $\times$ test time interaction $[F(1,22)=7.13, p<.05]$, reflecting higher P200 activity after categorization training than after individuation training. The training $\times$ hemisphere $[F(1,22)=5.46, p<.05]$ and time $\times$ hemisphere $[F(1,22)=6.50, p<.05]$ interactions were also significant (see Table 2). No other interactions were reliable. 
N250 Mean Activity ( $\mu$ V) Pre- vs. Postassessment

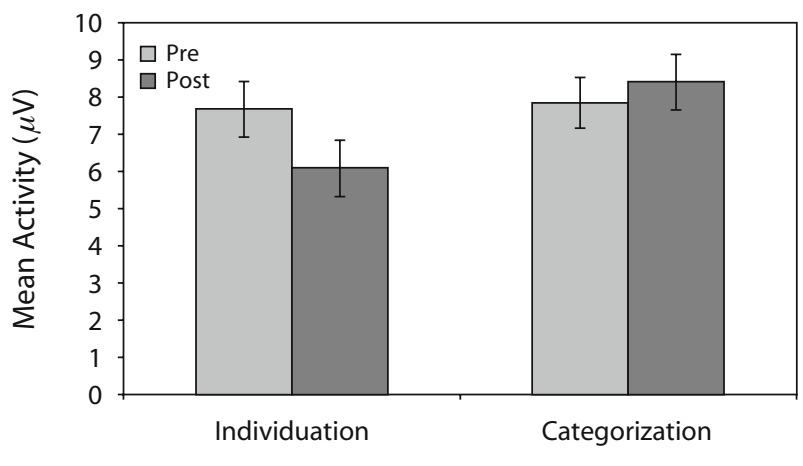

Condition

Figure 4. N250 mean activity $(\mu \mathrm{V})$ from pre- to postassessment for the individuation and categorization conditions.

N250 component. The N250 component is identified as the negative-going wave immediately following the P200 component, spanning a time window of approximately $100 \mathrm{msec}$ (Schweinberger et al., 2004; Scott et al., 2006; Tanaka et al., 2006). On the basis of visual inspection of the data, the N250 component was identified as the mean activity occurring $220-330$ msec post-stimulusonset. A repeated measures ANOVA was performed with the between-groups factor of individuated race (African American, Hispanic), in addition to the within-group factors of training, test time, and hemisphere. The variable of individuated race was not reliable, nor did it reliably interact with any of the other variables $(p>.05)$, indicating that there were no differences between the African American and Hispanic faces. The results indicated a main effect of training $[F(1,22)=11.92, p<.01]$ and hemisphere $[F(1,22)=5.81, p<.05]$. There was no main effect of test time $[F(1,22)=0.90, p>.10]$. Critically, there was a significant condition $\times$ test time interaction $[F(1,22)=18.18, p<.001]$, indicating that the individuation training showed a greater increased activity in the N250 component from pre- to postassessment, relative to categorization training (see Figures 4 and 5). No other interactions were reliable.

Planned comparisons confirmed this interpretation, in which the individuation and categorization training conditions were not significantly different at preassessment $(p>10)$. However, the individuation condition showed significantly greater $\mathrm{N} 250$ activity than did the categorization condition at postassessment $(p<.001)$. Moreover, whereas the difference between the pre- and posttraining N250 component was reliable in the individuation condition $(p<.001)$, the difference was not significant in the categorization condition $(p>.10)$ (see Figures 4 and 5).

The change in pre- and posttraining recognition of African American faces was reliably correlated with the change in magnitude of the $\mathrm{N} 250$ component $(r=-.426, p<.05$; as shown in Figure 6). Specifically, as other-race face recognition improved, there was a linear increase in the N250 amplitude. Although this pattern was observed only for recognition of the African American faces, other studies have suggested that enhancement of the N250 component is reliably linked to expert perception. For example, objecttraining studies have shown that as participants gain the perceptual skill to discriminate objects at the subordinate level, there is a significant increase in the N250 component (Scott et al., 2006, 2008). A recent study has also shown that when engaged in a difficult perceptual categorization task, the high learners (i.e., participants who successfully met the learning criterion) could be distinguished from the low learners (i.e., participants who failed to meet the training criterion) on the basis of the magnitudes of their N250 (Krigolson, Pierce, Holroyd, \& Tanaka, in press). These results suggest that the N250 reflects the formation of perceptual representations that support the fine-grained visual discriminations of the expert.

\section{DISCUSSION}

In this study, participants were trained to identify African American and Hispanic faces at either the basic level of race or the subordinate level of the individual. Prior to training, the participants did not differ in their ability to recognize African American and Hispanic faces. Although recognition of both African American and Hispanic faces improved after training, recognition of faces from the individuated race (African American or Hispanic) was su-

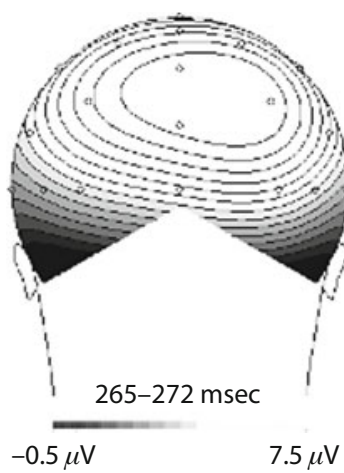

Individuation Post

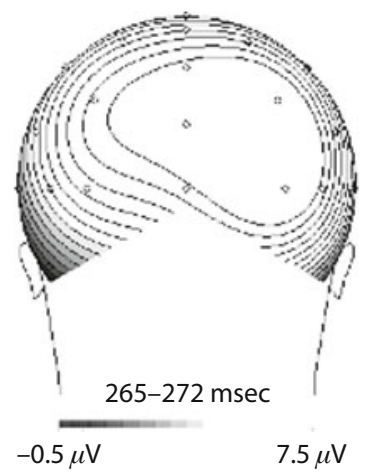

Categorization Post

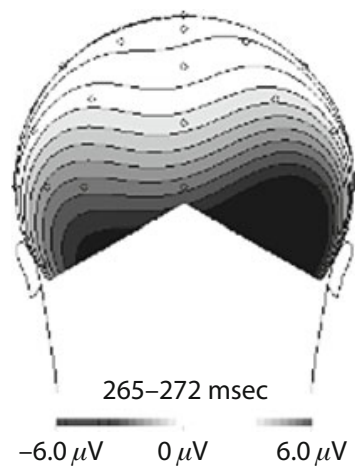

Individuation - Categorization Post

Figure 5. Topographical maps showing activity at postassessment for the individuation and categorization conditions (top panel) and the difference between the conditions at postassessment (bottom panel). 


\section{Relationship Between Change in $d^{\prime}$ and Change in N250 Amplitude From Pre- to Postassessment (African American Faces)}

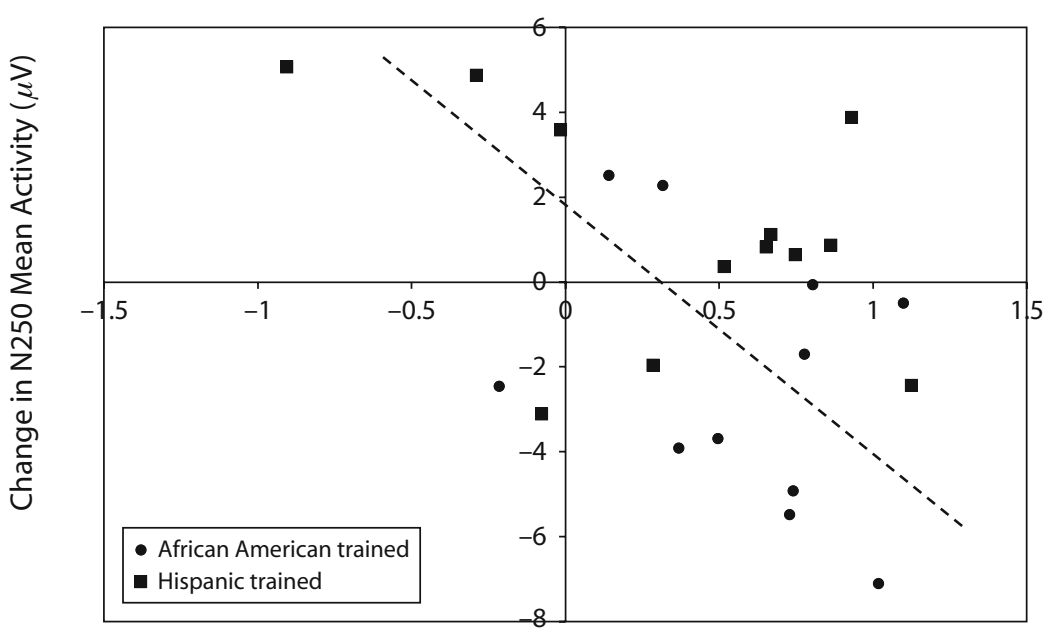

Change in $d^{\prime}$

Figure 6. Correlation between change in $d^{\prime}$ (i.e., posttraining recognition - pretraining recognition) and change in $\mathrm{N} 250$ mean activity $(\mu \mathrm{V})$ (i.e., posttraining amplitude - pretraining amplitude) for African American faces.

perior to recognition of faces from the categorized race. This result replicates findings from a previous other-race training study demonstrating that subordinate-level learning enhances the recognition of novel, other-race faces (Tanaka \& Droucker, 2009).

Other-race training also elicited changes in ERP processing components. After individuation and categorization training, the peak latency of the face N170 component to the African American and Hispanic faces occurred slightly earlier (pretraining, $166 \mathrm{msec}$; posttraining, $162 \mathrm{msec}$ ), suggesting that repeated exposure to otherrace faces affected the speed at which the face stimuli were accessed. However, the robustness of the latency effect is questionable, given that the overall difference of $4 \mathrm{msec}$ was equal to the $250-\mathrm{Hz}$ sampling rate. In contrast, training had no effect on the magnitude of the N170. This finding is consistent with previous results showing that own- versus other-race faces do not elicit differences on the face N170 component (Caldara et al., 2004; Caldara et al., 2003) or the related VPP (Ito et al., 2004). It has been speculated that the magnitude of the N170 provides an index of category experience in which experts show a greater N170 to objects in their domain of specialization than do novices (Scott et al., 2006, 2008; Tanaka \& Curran, 2001). Because most people are already "face experts," the modest amount of face experience provided in the face-training experiment pales in comparison with the lifetime of experience that people have with faces (Caldara et al., 2004; Caldara et al., 2003).

An unexpected finding was the greater left-hemisphere P200 component that was produced after categorization training. It has been suggested that this component might reflect the semantic information that is associated with a face (Caldara et al., 2004). Other researchers have hypoth- esized that the P200 plays a role in combining individual facial features into an integrative whole (Milivojevic, Clapp, Johnson, \& Corballis, 2003). However, neither of these interpretations explain why basic-level categorization training would enhance semantic processing or induce holistic perception.

Differences between individuation and categorization face training were most prominent in the N250 component. After learning to individuate African American or Hispanic faces, faces from the individuated race elicited a greater N250 component than did faces from the categorized race. This result is consistent with those of previous studies, in which the N250 was responsive to the identities of familiar people (Herzmann, Schweinberger, Sommer, \& Jentzsch, 2004; Schweinberger et al., 2004; Tanaka et al., 2006). The present results show that the N250 component extends beyond previously familiar faces and generalizes to new within-category faces as a consequence of individuation training. It is notable that this difference was recorded during administration of an old/new recognition test, in which, ostensibly, the participant's task is to individuate faces. Yet, because only faces from the individuated race, but not the categorized race, produced the heightened N250, this component appears to be influenced by prior training in subordinate-level categorization, and not by overt task demands.

The other-race N250 finding is analogous to the objecttraining results in which participants who learned to differentiate models of cars (Scott et al., 2008) or species of birds (Scott et al., 2006) produced an enhanced N250 to novel exemplars from the trained categories. In the present experiment, the N250 to individuated African American faces did not generalize to categorized Hispanic faces (or vice versa). Similarly, in the object-training studies, the 
enhanced N250 did not extend to exemplars from other basic-level categories (e.g., antique cars, if training was with subordinate-level sedans; or wading birds, if training was with subordinate-level owls). These findings suggest that the level of specificity as coded by the N250 is flexible and determined by categorization training.

This study sheds light on the important differences and similarities between face expertise and object expertise. Most people are face experts to the extent that they are exposed to hundreds of faces on an everyday basis and, over the years, have accumulated a vast catalog of experience to faces. Hence, as a neural correlate of face experience, the N170 is less affected by the additional exposure to other-race faces received during the training sessions. In contrast, people have less experience individuating faces from other racial groups. Our results show that training participants to individuate members from another race fostered an improved recognition of novel faces and elicited changes in the N250 component- the brain potential identified with expert perception and recognition.

To summarize, the present findings are compatible with a perceptual expertise account of the other-race effect. According to this view, as experts, we differentiate ownrace faces at the subordinate level of the individual, and as novices, we classify other-race faces at the basic level of race. As is predicted by Levin's (2000) feature-specific hypothesis, the contrasting levels of categorization influence perceptual processing of own- and other-race faces. Subordinate-level individuation promotes a finer level of perceptual encoding emphasizing the unique properties of a face, which in turn enhances the memorability of own-race faces. In contrast, categorization by race accentuates race-specific features (Fiset, Blais, Gosselin, Bub, \& Tanaka, 2008), deemphasizing the distinctive aspects of an individual face. Our findings suggest that the recognition of other-race faces by adults is not inflexible and unresponsive to perceptual experience but is adaptable and receptive to the effects of perceptual training. Indeed, a recent study indicates that individuation training can ameliorate negative biases implicitly associated with other-race faces (Lebrecht, Pierce, Tarr, \& Tanaka, 2009). Here, we have shown that subordinate-level training can improve the recognition of other-race faces and can produce changes in the ERP component associated with perceptual expertise.

\section{AUTHOR NOTE}

We thank the National Sciences and Engineering Research Council of Canada, the James S. McDonnell Foundation, and the Temporal Dynamics of Learning Center (NSF Grant SBE-0542013) for supporting this research. We also thank Deanna Barch, Tiffany Ito, and an anonymous reviewer for their helpful comments and advice. Also, we are grateful to members of the VizCogLab, Kim Maynard, Tommy Shrieves, Natasha Wawrykow, Natalie Huxtable, Magali Segers, Rebecca Phillips, Laura Dixon, and Sean Butler for their help with data collection. Correspondence concerning this article should be addressed to J. W. Tanaka, Department of Psychology, University of Victoria, P.O. Box 3050, STN CSC, Victoria, BC, V8W 3P5 Canada (e-mail: jtanaka@uvic.ca).

\section{REFERENCES}

Bentin, S., Allison, T., Puce, A., Perez, E., \& McCarthy, G. (1996).
Electrophysiological studies of face perception in humans. Journal of Cognitive Neuroscience, 8, 551-565.

Bentin, S., \& Deouell, L. (2000). Structural encoding and identification in face processing: ERP evidence for separate mechanism. Cognitive Neuropsychology, 17, 35-54.

Bonner, L., Burton, A. M., \& Bruce, V. (2003). Getting to know you: How we learn new faces. Visual Cognition, 10, 527-536.

Bothwell, R. K., Brigham, J. C., \& Malpass, R. S. (1989). Crossracial identification. Personality \& Social Psychology Bulletin, 15, 19-25.

Caldara, R., Rossion, B., Bovet, P., \& Hauert, C. A. (2004). Eventrelated potentials and time course of the "other-race" face classification advantage. NeuroReport, 15, 905-910.

Caldara, R., Thut, G., Servoir, P., Michel, C. M., Bovet, P., \& ReNAULT, B. (2003). Face versus non-face object perception and the "other-race" effect: A spatio-temporal event-related potential study. Clinical Neurophysiology, 114, 515-528.

Chiroro, P., \& Valentine, T. (1995). An investigation of the contact hypothesis of the own-race bias in face recognition. Quarterly Journal of Experimental Psychology, 48A, 879-894.

Correll, J., Urland, G. R., \& ITo, T. A. (2006). Event-related potentials and the decision to shoot: The role of threat perception and cognitive control. Journal of Experimental Social Psychology, 42, 120-128.

Cross, J. F., Cross, J., \& Daly, J. (1971). Sex, race, age, and beauty as factors in recognition of faces. Perception \& Psychophysics, 10, 393-396.

EIMER, M. (2000). Event-related brain potentials distinguish processing stages involved in face perception and recognition. Clinical Neurophysiology, 111, 694-705.

Fiset, D., Blais, C., Gosselin, F., Bub, D., \& Tanaka, J. (2008). Potent features for the categorization of Caucasian, African American, and Asian faces in Caucasian observers. Journal of Vision, 8, 258a.

Furl, N., Phillips, P. J., \& O'Toole, A. J. (2002). Face recognition algorithms and the other-race effect: Computational mechanisms for a developmental contact hypothesis. Cognitive Science, 26, 797-815.

Gratton, G., Coles, M. G. H., \& Donchin, E. (1983). A new method for off-line removal of ocular artifact. Electroencephalography \& Clinical Neurophysiology, 55, 468-484.

Herzmann, G., Schweinberger, S. R., Sommer, W., \& Jentzsch, I. (2004). What's special about personally familiar faces? A multimodal approach. Psychophysiology, 41, 688-701.

Ito, T. A., Thompson, E., \& CAciopro, J. T. (2004). Tracking the timecourse of social perception: The effects of racial cues on eventrelated brain potentials. Personality \& Social Psychology Bulletin, 30, 1267-1280.

Ito, T. A., \& URLAND, G. R. (2003). Race and gender on the brain: Electrocortical measures of attention to the race and gender of multiply categorizable individuals. Journal of Personality \& Social Psychology, 85, 616-626.

Ito, T. A., \& URLand, G. R. (2005). The influence of processing objectives on the perception of faces: An ERP study of race and gender perception. Cognitive, Affective, \& Behavioral Neuroscience, 5, 21-36.

James, M. S., Johnstone, S. J., \& Hayward, W. G. (2001). Eventrelated potentials, configural encoding, and feature-based encoding in face recognition. Journal of Psychophysiology, 15, 275-285.

Johnson, K., \& Mervis, C. (1997). Effects of varying levels of expertise on the basic level of categorization. Journal of Experimental Psychology: General, 126, 248-277.

Kaufmann, J. M., \& Schweinberger, S. R. (2008). Distortions in the brain? ERP effects of caricaturing familiar and unfamiliar faces. Brain Research, 1228, 177-188.

Krigolson, O. E., Pierce, L. J., Holroyd, C. B., \& Tanaka, J. W. (in press). Learning to become an expert: Reinforcement learning and the acquisition of perceptual expertise. Journal of Cognitive Neuroscience.

Lebrecht, S., Pierce, L. J., Tarr, M. J., \& Tanaka, J. W. (2009). Perceptual other-race training reduces implicit racial bias. PLOS ONE, 4, e4215. doi:10.1371/journal.pone.0004215

LEvin, D. T. (2000). Race as a visual feature: Using visual search and perceptual discrimination tasks to understand face categories and cross-race recognition deficit. Journal of Experimental Psychology: General, 129, 559-574. 
Maclin, O. H., Van Sickler, B. R., Maclin, M. K., \& Li, A. (2004). A re-examination of the cross-race effect: The role of race, inversion and basketball trivia. North American Journal of Psychology, 6, 189-204.

Meissner, C. A., \& Brigham, J. C. (2001). Thirty years of investigating the own-race bias in memory for faces: A meta-analytic review. Psychology, Public Policy \& Law, 7, 3-35.

Milivojevic, B., Clapp, W. C., Johnson, B. W., \& Corballis, M. C. (2003). Turn that frown upside down: ERP effects of thatcherization of misorientated faces. Psychophysiology, 40, 967-978.

NG, W., \& LindsaY, R. C. L. (1994). Cross-race facial recognition: Failure of the contact hypothesis. Journal of Cross-Cultural Psychology, 25, 217-232.

O'Donnell, C., \& Bruce, V. (2001). Familiarisation with faces selectively enhances sensitivity to changes made to the eyes. Perception, 30, 755-764.

O’Toole, A. J., Deffenbacher, K. A., Valentin, D., \& Abdi, H. (1994). Structural aspects of face recognition and the other-race effect. Memory \& Cognition, 22, 208-224.

Rossion, B., Joyce, C. A., Cottrell, G. W., \& Tarr, M. J. (2003). Early lateralization and orientation tuning for face, word, and object processing in the visual cortex. NeuroImage, 20, 1609-1624.

Schweinberger, S. R., Huddy, V., \& Burton, A. M. (2004). N250r: A face-selective brain response to stimulus repetitions. NeuroReport, 15, 1501-1505.

Schweinberger, S. R., Pickering, E. C., Jentzsch, I., Burton, A. M., \& Kaufmann, J. M. (2002). Event-related brain potential evidence for a response of inferior temporal cortex to familiar face repetitions. Cognitive Brain Research, 14, 398-409.

ScotT, L. S., Tanaka, J. W., Sheinberg, D. L., \& Curran, T. (2006). A reevaluation of the electrophysiological correlates of expert object processing. Journal of Cognitive Neuroscience, 18, 1453-1465.

Scott, L. S., TanaKa, J. W., Sheinberg, D. L., \& Curran, T. (2008). The role of category learning in the acquisition and retention of perceptual expertise: A behavioral and neurophysiological study. Brain \& Cognition, 1210, 204-215.

Slone, A. E., Brigham, J. C., \& Meissner, C. A. (2000). Social and cognitive factors affecting the own-race bias in Whites. Basic \& Applied Social Psychology, 22, 71-84.

TANAKA, J. W., \& CuRran, T. (2001). A neural basis for expert object recognition. Psychological Science, 12, 43-47.

Tanaka, J. W., Curran, T., Porterfield, A. L., \& Collins, D. (2006). Activation of preexisting and acquired face representations: The N250 event-related potential as an index of face familiarity. Journal of Cognitive Neuroscience, 18, 1488-1497.

TAnaka, J. W., Curran, T., \& Sheinberg, D. (2005). The training and transfer of real world perceptual expertise. Psychological Science, 16, 145-151.

TANaKa, J. W., \& Droucker, D. (2009). The plasticity of other-race face recognition in adults: A test of the perceptual expertise hypothesis. Manuscript submitted for publication.

TANAKA, J. W., \& TAYlor, M. (1991). Object categories and expertise: Is the basic level in the eye of the beholder? Cognitive Psychology, 23, 457-482.

Valentine, T. (1991). A unified account of the effects of distinctiveness, inversion, and race in face recognition. Quarterly Journal of Experimental Psychology, 43A, 161-204.

Walker, P. M., \& TANaKa, J. W. (2003). An encoding advantage for own-race versus other-race faces. Perception, 32, 1117-1125.

Wright, D. B., Boyd, C. E., \& Tredoux, C. G. (2001). A field study of own-race bias in South Africa and England. Psychology, Public Policy \& Law, 7, 119-133.

\section{NOTE}

1. The main effect of training cannot be interpreted, given that the first recognition test was administered before the training manipulation (individuation or categorization) was introduced. Interpretation of the training effect is meaningful only if it interacts with the test time factor (pretraining vs. posttraining).

(Manuscript received June 18, 2008; revision accepted for publication October 31, 2008.) 